\section{OPEN ACCESS}

Edited by:

Sha Wu,

Southern Medical University, China

Reviewed by:

Xiaocan Guo,

Harvard Medical School, United States

Yan Liu,

Harvard University, United States

*Correspondence:

Jiansong Ji

jijiansong@zju.edu.cn

Xiao-Jie Lu

189@whu.edu.cn

${ }^{\dagger}$ These authors share first authorship

Specialty section:

This article was submitted to Alloimmunity and Transplantation,

a section of the journal

Frontiers in Immunology

Received: 06 May 2021

Accepted: 15 July 2021

Published: 03 August 2021

Citation:

Sun J-Y, Wu R, Xu J, Xue H-Y, Lu X-J and Ji J (2021) Placental Immune Tolerance and Organ

Transplantation: Underlying Interconnections and

Clinical Implications.

Front. Immunol. 12:705950. doi: 10.3389/fimmu.2021.705950

\title{
Placental Immune Tolerance and Organ Transplantation: Underlying Interconnections and Clinical Implications
}

\begin{abstract}
Jin-Yu Sun ${ }^{1 \dagger}$, Rui $W^{1,2,3 \dagger}$, Jiang $X u^{4 \dagger}$, Hui-Ying Xue ${ }^{5}$, Xiao-Jie $\mathrm{Lu}^{6 *}$ and Jiansong $\mathrm{Ji}^{7 *}$
${ }^{1}$ Department of Cardiology, The First Affiliated Hospital of Nanjing Medical University, Nanjing, China, ${ }^{2}$ Department of Digestive Endoscopy, The First Affiliated Hospital of Nanjing Medical University, Nanjing, China, ${ }^{3}$ Department of General Surgery, The First Affiliated Hospital of Nanjing Medical University, Nanjing, China, ${ }^{4}$ Department of Rehabilitation, Huai'an Second People's Hospital and The Affiliated Huai'an Hospital of Xuzhou Medical University, Huai'an, China, ${ }^{5}$ The Reproductive Center, Huai'an Maternal and Child Health Care Hospital, Xuzhou Medical University, Huai'an, China, ${ }^{6}$ Department of General Surgery, Liver Transplantation Center, The First Affiliated Hospital of Nanjing Medical University, Naniing. China, ${ }^{7}$ Key Laboratory of Imaging Diagnosis and Minimally Invasive Intervention Research, Lishui Hospital of Zhejiang University/Fifth Affiliated Hospital of Wenzhou Medical University, Lishui, China
\end{abstract}

The immune system recognizes and attacks non-self antigens, making up the cornerstone of immunity activity against infection. However, during organ transplantation, the immune system also attacks transplanted organs and leads to immune rejection and transplantation failure. Interestingly, although the embryo and placenta are semiallografts, like transplanted organs, they can induce maternal tolerance and be free of a vigorous immune response. Also, embryo or placenta-related antibodies might adversely affect subsequent organ transplantation despite the immune tolerance during pregnancy. Therefore, the balance between the immune tolerance in maternal-fetal interface and normal infection defense provides a possible desensitization and tolerance strategy to improve transplantation outcomes. A few studies on mechanisms and clinical applications have been performed to explore the relationship between maternal-fetal immune tolerance and organ transplantation. However, up to now, the mechanisms underlying maternalfetal immune tolerance remain vague. In this review, we provide an overview on the current understanding of immune tolerance mechanisms underlying the maternal-fetal interface, summarize the interconnection between immune tolerance and organ transplantation, and describe the adverse effect of pregnancy alloimmunization on organ transplantation.

Keywords: placental immune tolerance, organ transplantation, immune rejection, clinical implication, maternalfetal interface

\section{INTRODUCTION}

The immune system recognizes, targets, and attacks non-self antigens, which makes up the fundamental of immunity activity against infection (1). However, the immune system also attacks transplanted organs, leading to immune rejection and transplant failure (2). The developing embryo and placenta could be considered semi-allografts (3), while it can induce 
maternal tolerance and be free of a vigorous immune response (4). The balance between the immune tolerance in the maternalfetal interface and normal infection defense plays a fundamental role in pregnancy (5), which inspires further research in the immune tolerance of maternal-fetal interface. Accumulating studies suggest that the tolerogenic mechanisms in the maternal-fetal interface are associated with and might be applied in organ transplantations. This review provides an overview of the current understanding of immune tolerance mechanisms underlying the maternal-fetal interface. Then, we summarize the interconnection between immune tolerance and organ transplantation. Finally, we describe the adverse effect of pregnancy alloimmunization on organ transplantation and discuss the current challenges.

\section{IMMUNE TOLERANCE MECHANISMS UNDERLYING THE MATERNAL-FETAL INTERFACE}

During pregnancy, the non-functional state of the primary immune cells (including decidual natural killer [ $\mathrm{dNK}]$ cells, decidual $\mathrm{T}$ cells, and decidual macrophages) induces placental immune tolerance, and the dNK cells are probably the most important in the many immune cells (6). Besides, immune tolerance synergistic molecules are another significant players in the maternal-fetal interface, such as HLA molecule and co-signaling molecules. HLA molecule is usually involved with host versus graft reaction, while the nonclassic major histocompatibility complex (MHC) class I molecule, HLA-G, was revealed to induce immune tolerance in the maternalfetal interface. Co-signaling molecules enhance the biological function of trophoblasts, decidual stromal cells, and decidual immune cells, while recent studies also revealed their roles in regulating placental immune tolerance.

\section{The Role of dNK Cells in Placental Immune Tolerance}

CD56 ${ }^{\text {bright }} \mathrm{CD} 16^{-} \mathrm{NK}$ cells are prominent NK cells (about $70 \%$ $80 \%$ of lymphocytes), which make up more than half of the maternal immune cells in human early pregnancy decidua (6). The origin of NK cells in the endometrium remains unclear. The $\mathrm{C}-\mathrm{X}-\mathrm{C}$ chemokine ligand 12 (CXCL12)/C-X-C chemokine receptor type 4 (CXCR4) axis is necessary to recruit $\mathrm{dNK}$ cells at the maternal-fetal interface. Tao et al. (7) obtained the decidual tissues from normal pregnancies (5-10 weeks) and revealed that CXCL12/CXCR4 axis could facilitate the migration of dNK cells concentration-dependent manner. CXCL12 could increase the migration of dNK cells by 1.2-, $1.4-$, and 1.9-fold at a concentration of 1,10 , and $100 \mathrm{ng} / \mathrm{ml}$, respectively (7). When trophoblast culture media were treated with anti-CXCR4, the chemotactic activity of dNK cells was significantly inhibited $(P<0.01)(7)$.

DNK cells were reported to play a central regulating role in decidual tolerance to embryos. During the first trimester, dNK cells participate in trophoblast invasion by producing chemokines (such as IL-8 and IL-10) without attacking placental cells $(8,9)$ since they would not polarize granules to the target cells (10). Co et al. (11) first revealed that the inhibited killing of dNK cells in invasive cytotrophoblasts was induced by maternal decidual macrophages cell, which provided a possible reason for the anergic dNK cells in placental immune. Placental (5-22 weeks) and decidual tissues (5-13 weeks) were achieved from patients undergoing elective terminations of pregnancy, and the dNK cells were cultured in vitro. The results showed that dNK cells could kill K562 target cells (leukemia cell lines) after removing macrophages, while the cytotoxicity of dNK cells was inhibited again when macrophages were added back. Furthermore, the addition of soluble TGF- $\beta 1$ to cytotoxicity assays had a significant inhibitory effect on purified dNKinduced cytotoxicity at a lower dNK: K562 ratio (5:1 vs. 20:1), and more primary cytotrophoblast targets (such as NK92 and K562) were attacked after removal of TGF- $\beta 1$, which suggested that the immune tolerance of $\mathrm{dNK}$ cells could be induced by TGF- $\beta 1$ (12). Wang et al. (13) obtained villi from healthy women receiving pregnancy termination (7-9 weeks) and extracted primary culture of first-trimester trophoblast cells. They reported that CXCL16 induced the polarization of M2 macrophages via inducing high IL-10 expression. Moreover, when dNK cells were co-cultured with M2 macrophage pretreated with rhCXCL16, the decreased expression of IL-15 facilitated the inactivation of $\mathrm{dNK}$ cells. These studies indicate the promoting role of macrophages in the dNK cell-induced immune tolerance at the maternal-fetal interface (Figure 1).

Recently, Huang et al. (14) recruited recurrent spontaneous abortion women $(n=49)$ and normal pregnant women $(n=52)$ and measured the expression of miR-30e in the decidua tissues via a quantitative polymerase chain reaction. They revealed that the expressions of miR-30e in individuals with recurrent spontaneous abortion were significantly decreased compared with the control group, and the cytotoxicity of dNK cells was reduced by upregulating miR-30e. Additionally, TiradoGonzalez et al. (15) reported that $\mathrm{dNK}$ cells induced apoptosis in decidua dendritic cells during pregnancy $(40.2 \pm 7.2 \%$ of DCSIGN $^{+}$cells in decidual sections and $34.4 \pm 15.2 \%$ in leukocyte suspensions), which induced the immune tolerance environment for the maternal-fetal interface.

Besides maintaining fetal tolerance, dNK cells might also contribute to the placental infection defense (16). Crespo et al. collected placental and decidual samples (6-12 weeks) and revealed that the antimicrobial peptide granulysin was highly expressed in human dNK cells. Antimicrobial peptide granulysin was selectively transferred via nanotubes to extravillous trophoblasts (EVTs) to kill intracellular Listeria monocytogenes without killing the trophoblasts $(17,18)$. Also, when pregnant women were infected with human cytomegalovirus (HCMV), the expression of killer cell immunoglobulin-like receptor 2DS1 (KIR2DS1) by dNK cells increased the ability to prevent placental HCMV infection. Similarly, the interaction between KIR2DS1 and HLA-C2 could enhance the activation of KIR2DS1 single-positive dNK and improve the response to placental HCMV infection (6-12 weeks human placental and decidual material) (19). 


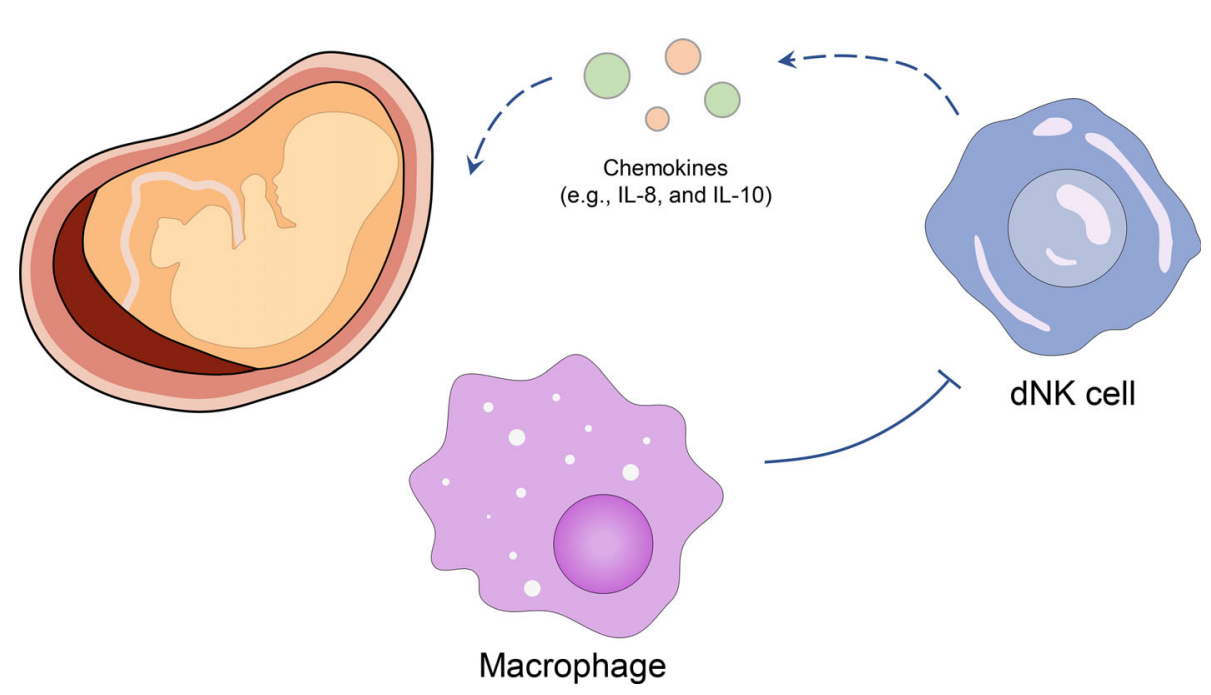

FIGURE 1 | Inhibitory effect of macrophages on dNK cells in the maternal-fetal interface. Macrophages induce the immune tolerance of dNK cells and decrease the chemokines (such as IL-8, and IL-10) in the maternal-fetal interface, thus stabilizing the embryo.

\section{The Role of Human Leukocyte Antigen in Placental Immune Tolerance}

Recently, accumulating studies are focused on the role of HLA in maternal-fetal immunity, especially HLA-G. EVT expresses a unique type of MHC molecules to induce immune tolerance. The tripartite interactions of human leukocyte antigen (HLA)-peptide-T cell receptors are fundamental in enabling the adaptive immune system, and MHC class I and II molecules could distinguish the self from the non-self antigen (Figure 2).

Regulation of HLA expression patterns is another potential strategy to inhibit organ transplantation rejection (20). Unlike most cells, EVTs do not express ubiquitous classical MHC class I molecules (i.e., HLA-A and HLA-B) (21). Instead, HLA-C and

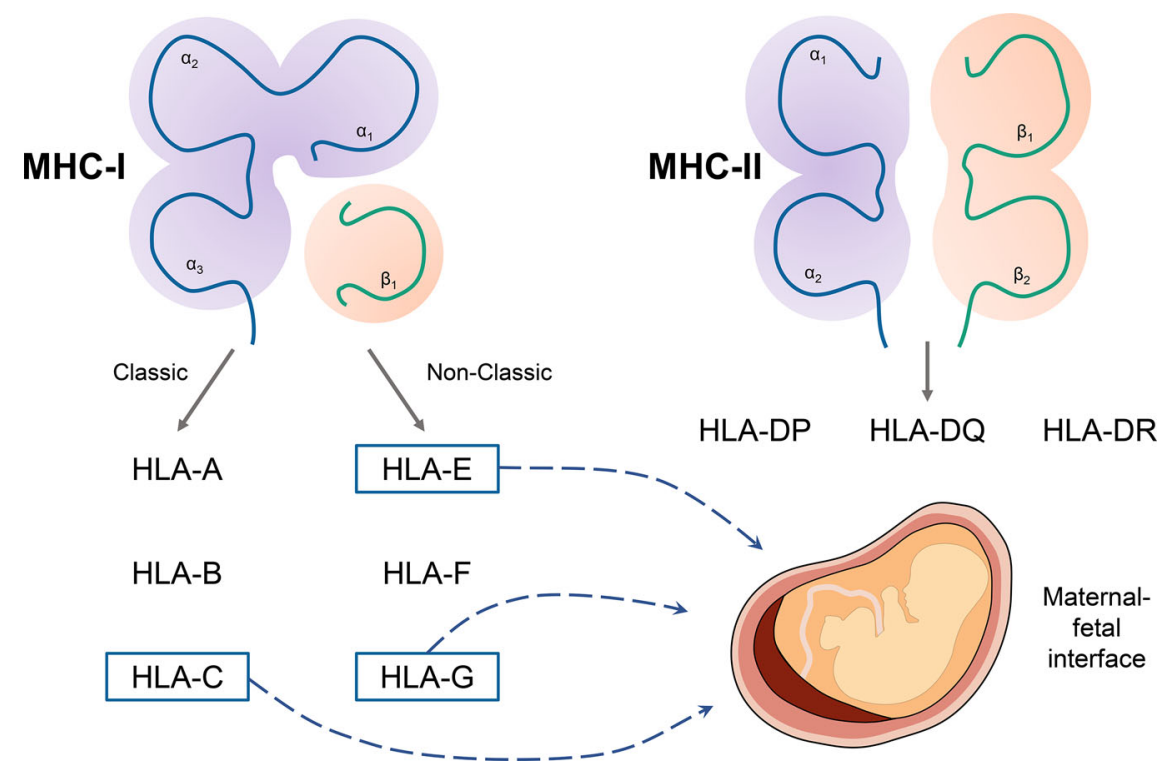

FIGURE 2 | The classification of major histocompatibility complex (MHC) molecules and main molecules in maternal-fetal immunity. MHC includes MHC class I and II molecules. Classic MHC class I molecules include human leukocyte antigen (HLA)-A, HLA-B, and HLA-C. The non-classic MHC class I molecules include HLA-E, HLA-F, and HLA-G. MHC class II molecules include HLA-DR, HLA -DP, HLA -DQ. HLA-C, HLA-E, and HLA-G play a significant role in immune tolerance in the maternal-fetal interface. 
the nonclassical MHC class I molecules (i.e., HLA-E and HLA-G) are expressed in EVTs. HLA-G shows great immunosuppressive features and a limited expression outside the trophoblasts (1). In the term pregnancy, HLA- $\mathrm{G}^{+}$EVTs have a weakened capacity to induce Treg via isolating three types of HLA-G $\mathrm{G}^{+}$EVTs from human placental tissues (HLA-G $\mathrm{G}^{+}$EVTs, 6 to 12 weeks, $\mathrm{n}=2$; HLA- $\mathrm{G}^{+}$EVTs, $>37$ weeks, $\mathrm{n}=3$; $\mathrm{HLA}^{-\mathrm{G}^{+}}$chorionic EVTs, $>37$ weeks, $n=3$ ), suggesting the distinct ability of HLA-G to enhance placental immune tolerance via directly inducing Treg cells (22). Meanwhile, the HLA-G could interact with decidual T cells, NK cells, macrophages, and dendritic cells and induce immune tolerance (23-25). Interestingly, Bortolotti et al. (26) isolated mesenchymal stromal/stem cells (MSCs) in endometrial decidual tissue (EDT) from menstrual blood collected from 5 healthy women during the first few days of the menstrual cycle. They reported that EDT-MSC could inhibit lymphocytes proliferation (70\% for low culture passage EDT-MSC, $40 \%$ for high culture passages EDT-MSC, $P<0.002$ ). Interestingly, when human EDT-MSCs were infected by the human herpesvirus (HSV)-1, the expression of HLA-G and its immunosuppressive function will be significantly reduced in a dosedependent manner.

Meanwhile, HLA-G is closely related to dNK cells in the maternal-fetal interface. Tilburgs et al. (27) collected human placental and decidual material (6-12 weeks), and the results showed that co-culture of activated dNK with EVTs could lead to the reacquisition of surface HLA-G. Meanwhile, co-culture of HLA-G-expressing melanoma M8 cells with dNK cells could restore the killer cell immunoglobulin-like receptor 2DL4 or immunoglobulin-like transcript 2 expression on dNK cells, which increased the expression levels of surface HLA-G. Therefore, the activation of $\mathrm{dNK}$ could decrease the internalized HLA-G and restore the cytotoxicity, and the HLA$\mathrm{G}$ could induce tolerance of dNK in turn.

\section{The Role of Co-Signaling Molecules in Placental Immune Tolerance}

Generally, immune cells can be fully activated after a second signal (co-signal) derived from the interaction between receptors on immune cells and the corresponding co-stimulating ligands on antigen-presenting cells. This classic 'two-signal model' is originated from the model of lymphocyte activation, which functions to optimize the immune response $(28,29)$. The potential co-signaling molecules mediating maternal-fetal immune tolerance are summarized in Table 1, including programmed death 1 (PD-1)/programmed death-ligand 1 (PDL1) (30-34), T cell immunoglobulin and mucin domain 3 (TIM3) (35-40), cytotoxic T-lymphocyte-associated antigen 4 (CTLA4) $(36,37,41)$, inducible co-stimulator (ICOS)/inducible costimulator ligand (ICOS-L) (42), carcinoembryonic Ag cell adhesion molecule 1 (CEACAM1) (43), and leukocyteassociated immunoglobulin like receptor-1 (LAIR-1) (44).

To the best of our acknowledge, PD-1/PD-L1 is probably the most studied among the many co-signaling molecules in maternal-fetal immunity (45). Meggyes et al. (35) used flow cytometry to measure PD-1 expression by peripheral and decidual immune cells from pregnant BALB-c mice on day 14.5 of pregnancy. The expression of PD-1 significantly increased in $\mathrm{dNK}$ cells $(P=0.001), \gamma / \delta \mathrm{T}$ cells $(P=0.002)$, and NKT cells $(P=0.024)$, thus reducing cytotoxic potential compared with the periphery. Interestingly, the upregulation of $\mathrm{PD}-1$ was consistent with the increase in maternal $\mathrm{T}$ cells in the decidua, which indicated a potential role for the PD-1/PD-L1 axis in silencing maternal immune responses to fetal antigens (46). In the following study by Costa et al. (47), the term (37-40 weeks), uncomplicated gestation placentas were obtained, and the results revealed that the PD-1/PD-L1 axis might limit $\mathrm{T}$ cell expansion and induce tolerance to the fetal allotransplant. Wang et al. (32) obtained the villous and decidual tissues from normal $(n=78)$ and miscarriages $(n=36)$ pregnancy. They reported that the co-culture of $\mathrm{CD} 8^{+} \mathrm{T}$ cells and trophoblasts could upregulate PD- $1^{+}$immune cells $(P<0.001)$. Blockade of Tim-3 and PD-1 decreased $\mathrm{CD}^{+} \mathrm{T}$ cell proliferation, enhanced trophoblast killing, and increased IFN- $\gamma$ production by $\mathrm{CD} 8^{+} \mathrm{T}$ cells. Then, they established a mouse pregnancy model by mating BALB/c males with $\mathrm{CBA} / \mathrm{J}$ females and reached the same conclusion in vivo. Sayama et al. (48) reported that production of IFN- $\gamma$ was suppressed in peripheral T cells when T cell-expressed PD-1 and macrophage-expressed PD-L1 interacted (Human first-trimester decidual samples, $n=10$ ), while the suppressive property was not observed in the monocytes lacking PD-L1. These studies demonstrated that PD-1/PD-L1 mediated immune tolerance as the co-signaling molecules. Besides, PD-L1 was reported to directly foster Treg differentiation and induce immune tolerance (49).

\section{THE RELATIONSHIP BETWEEN PLACENTAL IMMUNE TOLERANCE AND ORGAN TRANSPLANTATION}

Since HLA-G can maintain placental immune tolerance during pregnancy, it has been well explored as the promising diagnostic and even therapeutic target of organ transplantation. Ajith et al. (50) compared the expression of soluble HLA (sHLA)-G in patients with the immune rejection of the renal allograft $(n=40)$ and those with a functioning renal allograft $(n=90)$. The results showed that HLA-G could inhibit the activation and cytotoxic capabilities of human $\mathrm{CD}^{+} \mathrm{T}$ cells, one of the important mechanisms in organ transplantation rejection. Furthermore, Janssen et al. (51) genotyped 41 kidney recipients with acute rejection and 134 without rejection, and the results suggested that HLA-G polymorphisms were higher in recipients without acute rejection. Similarly, Durmanova et al. (52) reported that HLA-G polymorphisms were closely associated with graft acceptance. The sHLA-G level can predict the renal allograft outcome for high expression in patients with renal allograft $(31.6 \pm 20.2$ vs. $17.7 \pm 8.5, P=0.003)$. These studies suggest that HLA-G and its polymorphisms might play a potential protective role in organ transplantation (53). However, another study did not support the protective effect of HLA-G in liver transplantation since sHLA-G levels were higher 
TABLE 1 | Co-signaling molecules and their mechanism to induce the maternal-fetal immune tolerance.

\begin{tabular}{|c|c|}
\hline Cells & Co-signaling Molecules \\
\hline Trophoblasts & $\begin{array}{l}\text { Syncytiotrophoblasts: PD-L1, CD200, CD200R1, PD-L2 } \\
\text { Cytotrophoblasts: PD-L1, CD200, CD200R1 } \\
\text { EVTs: ICOS-L, PD-L1, CD276, CEACAM1, Gal-9, CD200, CD200R1, CD155, CD112 }\end{array}$ \\
\hline $\begin{array}{l}\text { Decidual stromal } \\
\text { cells }\end{array}$ & TIM-3, Gal-9, PD-L1, PD-L2 \\
\hline $\begin{array}{l}\text { Decidual immune } \\
\text { cells }\end{array}$ & $\begin{array}{l}\text { dNK cells: CEACAM1, TIM-3, LAIR-1, CD226 } \\
\text { Decidual T cells: PD-1, CEACAM-1, TIM-3, LAIR-1 } \\
\text { Decidual macrophages: LAIR-1 }\end{array}$ \\
\hline Main Molecules & Recent studies \\
\hline PD-1/PD-L1 & $\begin{array}{l}\text { Elevated PD-1 expression in decidual CD8 }{ }^{+} \mathrm{T}, \mathrm{CD} 4^{+} \mathrm{T} \text {, and NKT-like cells and PD-L1 expression in decidual CD4 }{ }^{+} \mathrm{T}, \mathrm{Treg} \text {, NKT-like and CD56 } \\
\text { NK cell compared to peripheral blood }(30) \text {. } \\
\text { The soluble PD-L1 increased in pregnant women and suppress maternal immunity (31). } \\
\text { Blockade of PD-1 resulted in decreased proliferation and Th2-type cytokine production while increased trophoblast killing and IFN- } \gamma \text { producing } \\
\text { capacities of CD8 }{ }^{+} \mathrm{T} \text { cells (32). } \\
\text { PD-1/PD-L1 signaling is critical for macrophage differentiation and function, which is the success of a pregnancy (33). } \\
\text { PD-1 promote Th2 bias and pregnancy maintenance by regulating CD4 }{ }^{+} \mathrm{T} \text { cell function at the maternal-fetal interface (34). }\end{array}$ \\
\hline TIM-3 & $\begin{array}{l}\text { Decidual NKT cells exhibit a reduced TIM-3 expression with increased relative receptor expression and a slightly increased cytotoxicity when } \\
\text { compared to the periphery (35). } \\
\text { TIM- } 3^{+} \mathrm{CTLA}-4^{+} \mathrm{dCD} 8^{+} \mathrm{T} \text { cells produced more anti-inflammatory cytokines. Blocking TIM-3 pathways inhibited the anti-inflammatory cytokines and } \\
\text { induced fetal loss (36). } \\
\text { TIM-3 pathways maintain tolerance by regulating dCD4 }{ }^{+} \text {T cells. Blockade of TIM-3 pathways induces fetal loss with altered cytokine profiles by } \\
\mathrm{dCD} 4^{+} \mathrm{T} \text { cells (37). } \\
\text { TIM-3 is upregulated in NK cells and inhibits NK cytotoxicity toward trophoblast in Gal-9 dependent pathway (38). } \\
\text { Activation of TLR signaling induced upregulated TIM-3 expression. TIM-3 inhibited TLR signaling-induced inflammatory cytokine production ( } 39 \text { ). } \\
\text { TIM-3 are expressed on over } 60 \% \text { of dNK cells. TIM-3 } 3^{+} \text {dNK cells display higher IL-4 and lower TNF- } \alpha \text { and perforin production. } \\
\text { Peripheral NK cells can be transformed into a dNK-like phenotype via Gal- } 9 \text { and the interaction between Gal- } 9 \text { and TIM-3. } \\
\text { Trophoblasts inhibit LPS-induced pro-inflammatory cytokine and perforin production by dNK cells, which can be attenuated by TIM-3 neutralizing } \\
\text { antibodies. } \\
\text { Th2-type cytokines decreased and Th1-type cytokines increased in TIM-3 } 3^{+} \text {dNK cells from human and mouse miscarriages (40). }\end{array}$ \\
\hline CTLA-4 & $\begin{array}{l}\text { Blocking CTLA-4 pathways inhibited the anti-inflammatory cytokines and induced fetal loss (36). } \\
\text { CTLA-4 pathways maintain tolerance by regulating dCD } 4^{+} T \text { cells. Blockade of CTLA-4 pathways induces fetal loss with altered cytokine profiles by } \\
\left.\text { dCD4 }{ }^{+} T \text { cells ( } 37\right) \text {. } \\
\text { Antigen-stimulated T cells become activated ligated with CD28 and anergic ligated with CTLA-4 (41). }\end{array}$ \\
\hline ICOS/ICOS-L & $\begin{array}{l}\text { ICOS-L blockade abrogates placental immune tolerance by enhancing CD8 }{ }^{+} \text {effector response and reducing local immunomodulation via CD } 8^{+} \\
\text {Treg cells (42). }\end{array}$ \\
\hline CEACAM1 & CEACAM1 interactions inhibit the lysis, proliferation, and cytokine secretion of activated dNK, $\mathrm{T}$, and NKT cells, respectively (43). \\
\hline LAIR-1 & Co-culture of dNK with primary TROs/DSCs downregulated Th1 cytokine production, which were abrogated by LAIR-1 inhibitor (44). \\
\hline
\end{tabular}

PD-L1, programmed death-ligand 1; CD200, cluster of differentiation-200; CD200R1, CD200 receptor 1; PD-L2, programmed death-ligand 2; ICOS-L, inducible co-stimulator ligand; CD276, cluster of differentiation-276; CEACAM1, carcinoembryonic Ag cell adhesion molecule 1; Gal-9, galectin-9; CD155, cluster of differentiation-155; CD112, cluster of differentiation112; TIM-3, T cell immunoglobulin and mucin domain 3; LAIR-1, leukocyte-associated immunoglobulin-like receptor-1; CD226, cluster of differentiation-226.

in recipients with acute rejection than nonrejectors (54). The authors claimed that it might be negative feedback to protect the liver against immunological damage (54).

Apart from the acute rejection, HLA-G can also predict the long-term prognosis of organ transplantation. Lazarte et al. (55) reported that sHLA-G increased in patients with chronic lung allograft dysfunction, and HLA-G single nucleotide polymorphism +3142 was associated with increased mortality (hazard ratio $[\mathrm{HR}]=1.78, P=0.015)$. Consistently, Brugiere et al. (56) and Ezeakile et al. (57) demonstrated that the HLA-G level and expression of the membrane-bound form of HLA-G on monocytes were related to the postoperative lifetime of kidney transplantation. Additionally, Adamson et al. (58) also found that HLA-G was a risk factor for cell-mediated rejection (CMR) following heart transplant in humans with a $P$-value of $0.03(\mathrm{n}=$ 123). Compared with the minor HLA-G $+3196 / G G$ genotype, the CG genotype had a $47.2 \%$ reduction in $\mathrm{CMR}$ risk $(\mathrm{HR}=$ $0.528,95 \%$ CI, 0.235-1.184), while CC genotype had a $66.9 \%$ reduction $(\mathrm{HR}=0.331,95 \% \mathrm{CI}, 0.144-0.761)$. The authors indicated that HLA-G might be considered a diagnostic strategy and a potential therapeutic target for transplant rejection. In the following research, Von et al. (59) firstly reported the therapeutic recombinant HLA-G5 in the intestinal transplantation model. Allogenic intestinal transplantation was performed in rats (Brown Norway to Lewis) with and without HLA-G treatment. The rats with HLA-G treatment showed significantly decreased postoperative acute rejection in 4 and 7 days after the operation, and acute rejection-related gene expression was higher in rats with HLA-G treatment (TNF $\alpha$, $P<0.05$; IL-10, $P<0.05$ ).

Moreover, NK cells and co-signaling molecules also induce immune tolerance in organ transplantation. For example, NK cells can induce both immune rejection and tolerance in liver transplantation (60). The recipient-derived NK cells tend to promote immune rejection, while the donor-derived NK cells tend to induce immune tolerance. Yazdani et al. (61) reported that the differential expression genes, which were identified in antibody-mediated rejection through bioinformatics pipeline 
(microarray transcriptomic data from a case-control study, $\mathrm{n}=95$ ), were enriched in NK cell pathways. Also, in multivariate cox analysis, NK cell infiltration could predict graft failure $(P<0.001)$ and diagnosis of rejection $(P=0.039)$ with the highest accuracy compared with other immune cell subtypes (e.g., $\mathrm{CD}^{+} \mathrm{T}$ cells, $\mathrm{CD} 4^{+} \mathrm{T}$ cells, macrophages, and so forth) according to the Banff classification.

Furthermore, the PD-1/PD-L1 axis induces placental immune tolerance and improves organ transplantation. In brief, the PD1/PD-L1 axis can induce tolerance in organ transplantation through PD-1 and CD28 gates and influence the effector T cells. Xu et al. (62) reported that cellular exosome-like nanovesicles could inhibit the proliferation of mononuclear cells in peripheral blood ( $76 \%$ vs. $2 \%, P<0.001)$ through the interaction of PD-1/PD-L1 and CTLA-4/CD80, which would subsequently decrease the density and activation of CD ${ }^{+} \mathrm{T}$ cells, downregulate cytokine production (HEK293T cells), and prolonged the survival of mouse skin and heart grafts. The blocked PD-1/PD-L1 axis could lead to a high rejection rate [37\% to $80 \%(63)]$ for transplanted organs. A recent metaanalysis (64) reviewed the VigiBase database to explore the association of rejection events with drugs and revealed that anti-PD-1 and anti-PD-L1 drugs were more involved compared with anti-CTLA-4 drugs in rejection events $(93.0 \%$ vs. $7.0 \%$ ) due to the blockade of the specific pathway.

\section{THE ADVERSE EFFECT OF PREGNANCY ALLOIMMUNIZATION ON ORGAN TRANSPLANTATION}

Despite the immune tolerance during pregnancy, alloimmunization also exists, which might induce an increased risk for future organ transplantation rejection (65). Studies (6671) regarding the adverse effect of pregnancy on subsequent organ transplantation are summarized in Table 2.

A study including 69 participants based on the Luminex screening test showed that about $24 \%$ to $49 \%$ of parous transplant candidates have the detectable anti-HLA antibody, which composed a barrier to transplant success due to pregnancy alloimmunization (72). Redfield et al. (68) reported that retransplants (53\%), pregnancy (20\%), and transfusion (5\%) were the three main reasons for high sensitivity to kidney transplantation (patients with a panel reactive antibody $\geq$ $98 \%$ ). The rate of organ transplantation rejection increased in highly sensitized patients within one year compared with those non-sensitized ( $10.6 \%$ vs. $8.3 \%, P<0.001)$. The 10 -year survival rate of highly sensitized patients was also significantly worse $(43.9 \%$ vs. $52.4 \%, P<0.001)$. A study of 2,587 kidney transplant candidates suggested that the rate of living donor kidney transplantation for women decreased by $30 \%$ due to histocompatibility (67). Retransplants, pregnancy, and transfusion all contribute to the high sensitivity to transplantation, and retransplants have a more significant immunologic impact, followed by pregnancy and transfusion (73). However, in practice, spouses are often the primary transplant source, and pregnancy is the unique cause of sex disparity in organ transplantation (67).

Meanwhile, Van et al. (74) reported that the incidence of kidney graft loss was $9.4 \%$ within two years, $9.2 \%$ within $2-5$ years, and $22.3 \%$ within 5-10 years after pregnancy, respectively. They pointed that pregnancy affected the graft loss significantly within two years. Furthermore, when comparing male and female recipients with $0 \%$ panel reactive antibody, there was no significant difference in all-cause graft failure (66), which indirectly indicated that pregnancy alloimmunization might negatively impact the subsequent transplantation process after pregnancy.

\section{CONCLUSION}

Currently, the survival of patients receiving organ transplantation remains unsatisfactory, with a five-year survival of $89.6 \%$ (75), $86.6 \%$ (76), and $77 \%$ (77) in the liver, kidney, and heart transplantation, respectively. Although immunosuppression has been widely used to inhibit acute graft- $v s$-host disease after organ transplantation (78), many complications (like heart failure or acute kidney injury) increase morbidity and mortality (79). Longterm immunosuppression treatment is likely to cause many graftor host-related adverse events, such as bone mass loss (80), infection (81), and malignancies (82). Patients with organ transplants have an approximately 2 -fold increased cancer risk than the general population $(83,84)$. The interconnection between

TABLE 2 | Adverse effect of pregnancy on subsequent organ transplantation.

\begin{tabular}{|c|c|c|c|c|c|}
\hline Author & Type & Study time & $\begin{array}{l}\text { Sample } \\
\text { size }\end{array}$ & $\begin{array}{l}\text { Type of } \\
\text { organ }\end{array}$ & Conclusion \\
\hline Cohen et al. (66) & Retrospective & 2001-2013 & 5012 & Kidney & No difference in graft failure between recipients of fathers and mothers. \\
\hline Bromberger et al. (67) & Retrospective & $2007-2013$ & 502 & Kidney & Pregnancy is the major reason for loss of living donor access for women. \\
\hline Redfield et al. (68) & $\begin{array}{l}\text { Dataset } \\
\text { analysis }\end{array}$ & 1997-2014 & 107292 & Kidney & $\begin{array}{l}\text { Pregnancy alone is made up } 20 \% \text { of sensitization; Waiting time for organ } \\
\text { transplantation is longer for women. }\end{array}$ \\
\hline Higgins et al. (69) & Retrospective & 2003-2012 & 64 & No mention & $\begin{array}{l}\text { Pregnancy leads to the greatest increase in HLA antibody levels from pre-treatment to } \\
\text { peak }\end{array}$ \\
\hline Choi et al. (70) & Retrospective & 1979-2011 & 374 & Kidney & $\begin{array}{l}\text { The antibody originated from the sensitization in pregnancy results in the } \\
\text { transplantation failure. }\end{array}$ \\
\hline Ghafari et al. (71) & Retrospective & 1989-2006 & 171 & Kidney & Graft survival time was significantly worse because of pregnancy \\
\hline
\end{tabular}

HLA, human leukocyte antigen. 
A

Annual scientific production

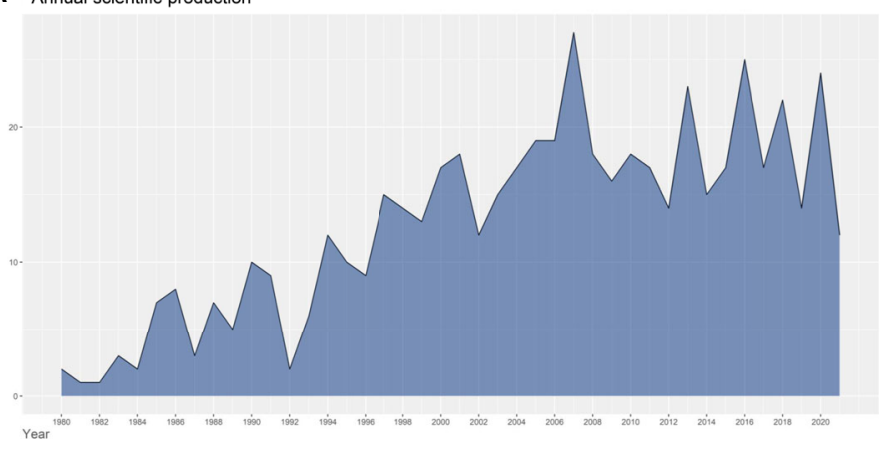

C Country scientific production
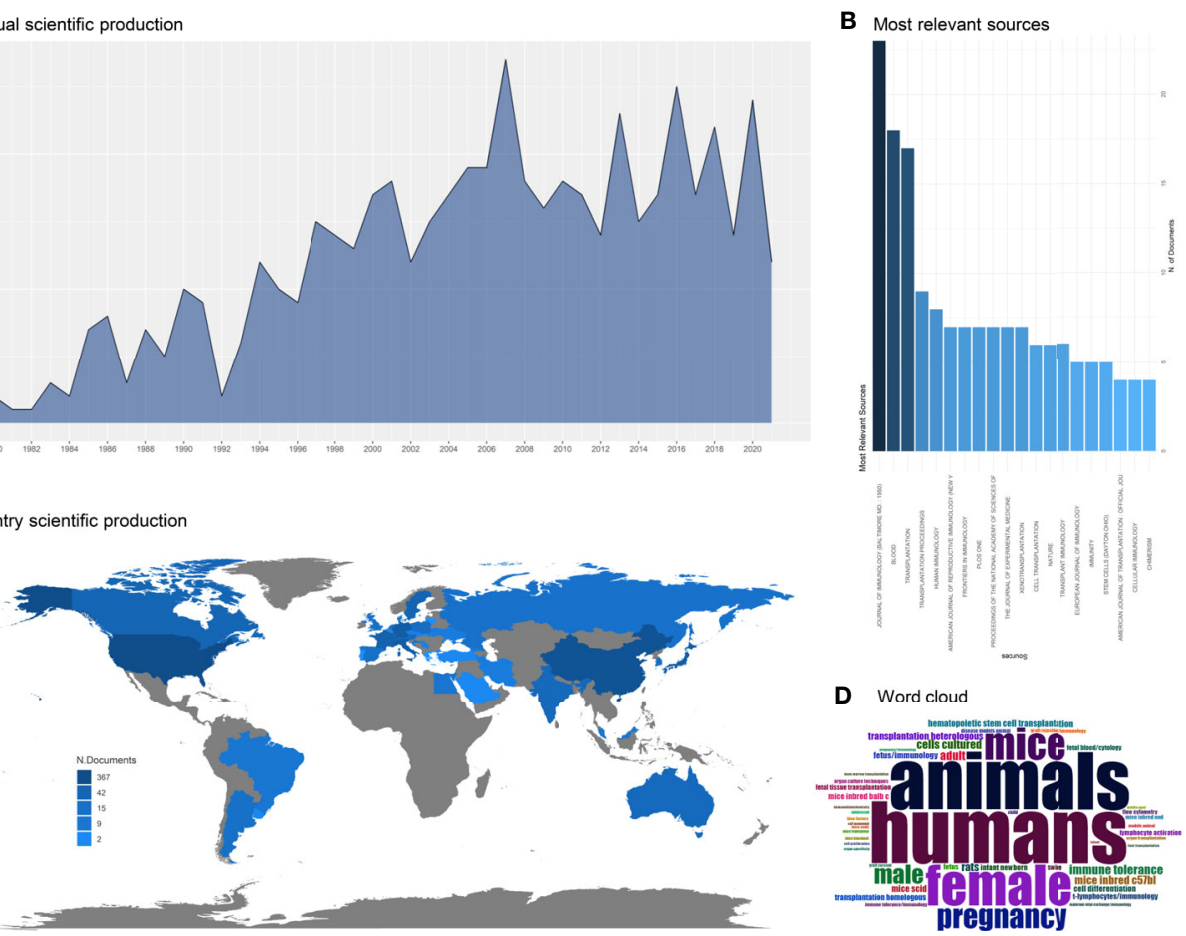

D Word cloud

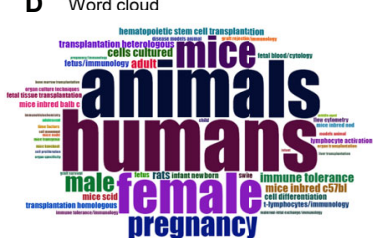

FIGURE 3 | Trends of the research in placental immunity and organ transplantation. The search strategy is (((((fetal) OR (placenta*)) OR (maternal-fetal interface)) AND (immune)) AND (organ)) AND (transplantation)) AND ((“1980”[Date - Publication]: "2021"[Date - Publication])). (A) The annual scientific production shows an increasing trend from 1980 to 2021. (B) The most relevant sources of these published studies. The top three relevant sources are Journal of immunology, Blood, and Transplantation. (C) Country scientific production. The color indicates the number of the related studies in each country. (D) Word cloud is based on the keywords from the published studies.

placental immunity and transplantation immunity has recently become a hot topic since it might provide a potential strategy to regulate the immune balance between the hosts and transplanted organs. This article provides an overview on the current understanding of immune tolerance mechanisms underlying the maternal-fetal interface. We review the immune tolerance mechanisms of $\mathrm{dNK}$ cells and immune tolerance synergistic molecules (such as HLA molecule and co-signaling molecules), and we summarize current evidence on the relationship between immune tolerance and organ transplantation. Finally, we describe the adverse effect of pregnancy alloimmunization on organ transplantation.

Still, it should be highlighted that the total view of the mechanisms underlying placental immunity remains vague. The immune tolerance in the maternal-fetal interface is a complex balance associated with both the immune tolerance molecules and immune microenvironment. However, most

\section{REFERENCES}

1. Munoz-Suano A, Hamilton AB, Betz AG. Gimme Shelter: The Immune System During Pregnancy. Immunol Rev (2011) 241:20-38. doi: 10.1111/ j.1600-065X.2011.01002.x

2. Abdolmohammadi-Vahid S, Danaii S, Hamdi K, Jadidi-Niaragh F, Ahmadi M, Yousefi M. Novel Immunotherapeutic Approaches for Treatment of studies were performed on a cellular level, and there lacks enough validation in mature animal models. Only a few immune tolerance molecules in the maternal-fetal interface have been studied. Besides, the studies regarding the application of placental immunity on organ transplantation are limited (Figure 3). Accordingly, further in vivo experiments using animal models are necessary, and more immune pathways and immune networks should be explored.

\section{AUTHOR CONTRIBUTIONS}

J-YS, RW, and X-JL developed the study concept. RW wrote the manuscript with the help of J-YS, JX, H-YX, X-JL, and JJ. All authors contributed to the article and approved the submitted version. 
5. Parker EL, Silverstein RB, Verma S, Mysorekar IU. Viral-Immune Cell Interactions at the Maternal-Fetal Interface in Human Pregnancy. Front Immunol (2020) 11:522047. doi: 10.3389/fimmu.2020.522047

6. Liu S, Diao L, Huang C, Li Y, Zeng Y, Kwak-Kim J. The Role of Decidual Immune Cells on Human Pregnancy. J Reprod Immunol (2017) 124:44-53. doi: 10.1016/j.jri.2017.10.045

7. Tao Y, Li YH, Piao HL, Zhou WJ, Zhang D, Fu Q, et al. CD56(Bright)CD25+ NK Cells Are Preferentially Recruited to the Maternal/Fetal Interface in Early Human Pregnancy. Cell Mol Immunol (2015) 12:77-86. doi: 10.1038/ cmi.2014.26

8. Hanna J, Goldman-Wohl D, Hamani Y, Avraham I, Greenfield C, NatansonYaron S, et al. Decidual NK Cells Regulate Key Developmental Processes at the Human Fetal-Maternal Interface. Nat Med (2006) 12:1065-74. doi: $10.1038 / \mathrm{nm} 1452$

9. Yang F, Zheng Q, Jin L. Dynamic Function and Composition Changes of Immune Cells During Normal and Pathological Pregnancy at the MaternalFetal Interface. Front Immunol (2019) 10:2317. doi: 10.3389/ fimmu.2019.02317

10. Kopcow HD, Allan DS, Chen X, Rybalov B, Andzelm MM, Ge B, et al. Human Decidual NK Cells Form Immature Activating Synapses and Are Not Cytotoxic. Proc Natl Acad Sci U S A (2005) 102:15563-8. doi: 10.1073/ pnas.0507835102

11. Co EC, Gormley M, Kapidzic M, Rosen DB, Scott MA, Stolp HA, et al. Maternal Decidual Macrophages Inhibit NK Cell Killing of Invasive Cytotrophoblasts During Human Pregnancy. Biol Reprod (2013) 88:155. doi: 10.1095/biolreprod.112.099465

12. PrabhuDas M, Bonney E, Caron K, Dey S, Erlebacher A, Fazleabas A, et al. Immune Mechanisms at the Maternal-Fetal Interface: Perspectives and Challenges. Nat Immunol (2015) 16:328-34. doi: 10.1038/ni.3131

13. Wang XQ, Zhou WJ, Hou XX, Fu Q, Li DJ. Trophoblast-Derived CXCL16 Induces M2 Macrophage Polarization That in Turn Inactivates NK Cells at the Maternal-Fetal Interface. Cell Mol Immunol (2018) 15:1038-46. doi: 10.1038/ s41423-018-0019-x

14. Huang Q, Ding J, Gong M, Wei M, Zhao Q, Yang J. Effect of miR-30e Regulating NK Cell Activities on Immune Tolerance of Maternal-Fetal Interface by Targeting PRF1. BioMed Pharmacother (2019) 109:1478-87. doi: 10.1016/j.biopha.2018.09.172

15. Tirado-Gonzalez I, Munoz-Fernandez R, Prados A, Leno-Duran E, Martin F, Abadia-Molina AC, et al. Apoptotic DC-SIGN+ Cells in Normal Human Decidua. Placenta (2012) 33:257-63. doi: 10.1016/j.placenta.2012.01.003

16. Crespo AC, van der Zwan A, Ramalho-Santos J, Strominger JL, Tilburgs T. Cytotoxic Potential of Decidual NK Cells and CD8+ T Cells Awakened by Infections. J Reprod Immunol (2017) 119:85-90. doi: 10.1016/j.jri.2016.08.001

17. Crespo AC, Mulik S, Dotiwala F, Ansara JA, Sen SS, Ingersoll K, et al. Decidual NK Cells Transfer Granulysin to Selectively Kill Bacteria in Trophoblasts. Cell (2020) 182:1125-39. doi: 10.1016/j.cell.2020.07.019

18. Dogra P, Farber DL. Stealth Killing by Uterine NK Cells for Tolerance and Tissue Homeostasis. Cell (2020) 182:1074-6. doi: 10.1016/j.cell.2020.08.018

19. Crespo AC, Strominger JL, Tilburgs T. Expression of KIR2DS1 by Decidual Natural Killer Cells Increases Their Ability to Control Placental HCMV Infection. Proc Natl Acad Sci U S A (2016) 113:15072-7. doi: 10.1073/ pnas. 1617927114

20. Dendrou CA, Petersen J, Rossjohn J, Fugger L. HLA Variation and Disease. Nat Rev Immunol (2018) 18:325-39. doi: 10.1038/nri.2017.143

21. Apps R, Murphy SP, Fernando R, Gardner L, Ahad T, Moffett A. Human Leucocyte Antigen (HLA) Expression of Primary Trophoblast Cells and Placental Cell Lines, Determined Using Single Antigen Beads to Characterize Allotype Specificities of Anti-HLA Antibodies. Immunology (2009) 127:26-39. doi: 10.1111/j.1365-2567.2008.03019.x

22. Papuchova H, Kshirsagar S, Xu L, Bougleux GH, Li Q, Iyer V, et al. Three Types of HLA-G+ Extravillous Trophoblasts That Have Distinct Immune Regulatory Properties. Proc Natl Acad Sci U S A (2020) 117:15772-7. doi: $10.1073 /$ pnas. 2000484117

23. Hackmon R, Pinnaduwage L, Zhang J, Lye SJ, Geraghty DE, Dunk CE. Definitive Class I Human Leukocyte Antigen Expression in Gestational Placentation: HLA-F, HLA-E, HLA-C, and HLA-G in Extravillous Trophoblast Invasion on Placentation, Pregnancy, and Parturition. Am J Reprod Immunol (2017) 77:e12643. doi: 10.1111/aji.12643
24. Djurisic S, Hviid TV. HLA Class Ib Molecules and Immune Cells in Pregnancy and Preeclampsia. Front Immunol (2014) 5:652. doi: 10.3389/fimmu.2014.00652

25. Johnsen GM, Fjeldstad H, Drabbels J, Haasnoot GW, Eikmans M, Storvold GL, et al. A Possible Role for HLA-G in Development of Uteroplacental Acute Atherosis in Preeclampsia. J Reprod Immunol (2021) 144:103284. doi: 10.1016/j.jri.2021.103284

26. Bortolotti D, Rossignoli F, Rotola A, Campioni D, Cultrera R, Grisendi G, et al. Human Herpes Simplex 1 Virus Infection of Endometrial Decidual TissueDerived MSC Alters HLA-G Expression and Immunosuppressive Functions. Hum Immunol (2018) 79:800-8. doi: 10.1016/j.humimm.2018.08.006

27. Tilburgs T, Evans JH, Crespo AC, Strominger JL. The HLA-G Cycle Provides for Both NK Tolerance and Immunity at the Maternal-Fetal Interface. Proc Natl Acad Sci U S A (2015) 112:13312-7. doi: 10.1073/pnas.1517724112

28. Huang X, Zhang X, Li E, Zhang G, Wang X, Tang T, et al. VISTA: An Immune Regulatory Protein Checking Tumor and Immune Cells in Cancer Immunotherapy. J Hematol Oncol (2020) 13:83. doi: 10.1186/s13045-02000917-y

29. Chen L, Flies DB. Molecular Mechanisms of T Cell Co-Stimulation and CoInhibition. Nat Rev Immunol (2013) 13:227-42. doi: 10.1038/nri3405

30. Meggyes M, Miko E, Szigeti B, Farkas N, Szereday L. The Importance of the PD-1/PD-L1 Pathway at the Maternal-Fetal Interface. BMC Pregnancy Childbirth (2019) 19:74. doi: 10.1186/s12884-019-2218-6

31. Okuyama M, Mezawa H, Kawai T, Urashima M. Elevated Soluble PD-L1 in Pregnant Women's Serum Suppresses the Immune Reaction. Front Immunol (2019) 10:86. doi: 10.3389/fimmu.2019.00086

32. Wang SC, Li YH, Piao HL, Hong XW, Zhang D, Xu YY, et al. PD-1 and Tim-3 Pathways are Associated With Regulatory CD8+ T-Cell Function in Decidua and Maintenance of Normal Pregnancy. Cell Death Dis (2015) 6:e1738. doi: 10.1038/cddis.2015.112

33. Zhang Y, Ma L, Hu X, Ji J, Mor G, Liao A. The Role of the PD-1/PD-L1 Axis in Macrophage Differentiation and Function During Pregnancy. Hum Reprod (2019) 34:25-36. doi: 10.1093/humrep/dey347

34. Wang S, Zhu X, Xu Y, Zhang D, Li Y, Tao Y, et al. Programmed Cell Death-1 (PD-1) and T-Cell Immunoglobulin Mucin-3 (Tim-3) Regulate CD4+ T Cells to Induce Type 2 Helper T Cell (Th2) Bias at the Maternal-Fetal Interface. Hum Reprod (2016) 31:700-11. doi: 10.1093/humrep/dew019

35. Meggyes M, Lajko A, Palkovics T, Totsimon A, Illes Z, Szereday L, et al. FetoMaternal Immune Regulation by TIM-3/galectin-9 Pathway and PD-1 Molecule in Mice at Day 14.5 of Pregnancy. Placenta (2015) 36:1153-60. doi: 10.1016/j.placenta.2015.07.124

36. Wang S, Sun F, Li M, Qian J, Chen C, Wang M, et al. The Appropriate Frequency and Function of Decidual Tim-3(+)CTLA-4(+)CD8(+) T Cells are Important in Maintaining Normal Pregnancy. Cell Death Dis (2019) 10:407. doi: 10.1038/s41419-019-1642-x

37. Wang S, Chen C, Li M, Qian J, Sun F, Li Y, et al. Blockade of CTLA-4 and Tim-3 Pathways Induces Fetal Loss With Altered Cytokine Profiles by Decidual CD4(+)T Cells. Cell Death Dis (2019) 10:15. doi: 10.1038/s41419018-1251-0

38. Sun J, Yang M, Ban Y, Gao W, Song B, Wang Y, et al. Tim-3 Is Upregulated in NK Cells During Early Pregnancy and Inhibits NK Cytotoxicity Toward Trophoblast in Galectin-9 Dependent Pathway. PloS One (2016) 11:e147186. doi: 10.1371/journal.pone.0147186

39. Wang S, Cao C, Piao H, Li Y, Tao Y, Zhang X, et al. Tim-3 Protects Decidual Stromal Cells From Toll-Like Receptor-Mediated Apoptosis and Inflammatory Reactions and Promotes Th2 Bias at the Maternal-Fetal Interface. Sci Rep (2015) 5:9013. doi: 10.1038/srep09013

40. Li YH, Zhou WH, Tao Y, Wang SC, Jiang YL, Zhang D, et al. The Galectin-9/ Tim-3 Pathway Is Involved in the Regulation of NK Cell Function at the Maternal-Fetal Interface in Early Pregnancy. Cell Mol Immunol (2016) 13:7381. doi: $10.1038 / \mathrm{cmi} .2014 .126$

41. Petroff MG, Perchellet A. B7 Family Molecules as Regulators of the Maternal Immune System in Pregnancy. Am J Reprod Immunol (2010) 63:506-19. doi: 10.1111/j.1600-0897.2010.00841.x

42. Riella LV, Dada S, Chabtini L, Smith B, Huang L, Dakle P, et al. B7h (ICOS-L) Maintains Tolerance at the Fetomaternal Interface. Am J Pathol (2013) 182:2204-13. doi: 10.1016/j.ajpath.2013.02.014

43. Markel G, Wolf D, Hanna J, Gazit R, Goldman-Wohl D, Lavy Y, et al. Pivotal Role of CEACAM1 Protein in the Inhibition of Activated Decidual 
Lymphocyte Functions. J Clin Invest (2002) 110:943-53. doi: 10.1172/ JCI0215643

44. Fu Q, Sun Y, Tao Y, Piao H, Wang X, Luan X, et al. Involvement of the JAKSTAT Pathway in Collagen Regulation of Decidual NK Cells. Am J Reprod Immunol (2017) 78:e12769. doi: 10.1111/aji.12769

45. Sun JY, Zhang D, Wu S, Xu M, Zhou X, Lu XJ, et al. Resistance to PD-1/PD-L1 Blockade Cancer Immunotherapy: Mechanisms, Predictive Factors, and Future Perspectives. Biomark Res (2020) 8:35. doi: 10.1186/s40364-02000212-5

46. Holets LM, Hunt JS, Petroff MG. Trophoblast CD274 (B7-H1) Is Differentially Expressed Across Gestation: Influence of Oxygen Concentration. Biol Reprod (2006) 74:352-8. doi: 10.1095/biolreprod.105.046581

47. Costa ML, Robinette ML, Bugatti M, Longtine MS, Colvin BN, Lantelme E, et al. Two Distinct Myeloid Subsets at the Term Human Fetal-Maternal Interface. Front Immunol (2017) 8:1357. doi: 10.3389/fimmu.2017.01357

48. Sayama S, Nagamatsu T, Schust DJ, Itaoka N, Ichikawa M, Kawana K, et al. Human Decidual Macrophages Suppress IFN-gamma Production by T Cells Through Costimulatory B7-H1:PD-1 Signaling in Early Pregnancy. J Reprod Immunol (2013) 100:109-17. doi: 10.1016/j.jri.2013.08.001

49. Zhang YH, Tian M, Tang MX, Liu ZZ, Liao AH. Recent Insight Into the Role of the PD-1/PD-L1 Pathway in Feto-Maternal Tolerance and Pregnancy. Am J Reprod Immunol (2015) 74:201-8. doi: 10.1111/aji.12365

50. Ajith A, Portik-Dobos V, Nguyen-Lefebvre AT, Callaway C, Horuzsko DD, Kapoor R, et al. HLA-G Dimer Targets Granzyme B Pathway to Prolong Human Renal Allograft Survival. FASEB J (2019) 33:5220-36. doi: 10.1096/ fj.201802017R

51. Janssen M, Thaiss F, Nashan B, Koch M, Thude H. Donor Derived HLA-G Polymorphisms Have a Significant Impact on Acute Rejection in Kidney Transplantation. Hum Immunol (2019) 80:176-83. doi: 10.1016/ j.humimm.2018.12.011

52. Durmanova V, Bandzuchova H, Zilinska Z, Tirpakova J, Kuba D, Buc M, et al. Association of HLA-G Polymorphisms in the 3'UTR Region and Soluble HLA-G With Kidney Graft Outcome. Immunol Invest (2019) 48:644-58. doi: 10.1080/08820139.2019.1610888

53. Hauer V, Risti M, Miranda B, Da SJ, Cidral AL, Pozzi CM, et al. The Association of HLA-G Polymorphisms and the Synergistic Effect of sMICA and sHLA-G With Chronic Kidney Disease and Allograft Acceptance. PloS One (2019) 14:e212750. doi: 10.1371/journal.pone.0212750

54. Moroso V, van Cranenbroek B, Mancham S, Sideras K, Boor PP, Biermann K, et al. Prominent HLA-G Expression in Liver Disease But Not After Liver Transplantation. Transplantation (2015) 99:2514-22. doi: 10.1097/ TP.0000000000000761

55. Lazarte J, Ma J, Martinu T, Levy L, Klement W, White M, et al. Donor Human Leukocyte Antigen-G Single Nucleotide Polymorphisms are Associated With Post-Lung Transplant Mortality. Eur Respir J (2019) 54:1802126. doi: 10.1183/ 13993003.02126-2018

56. Brugiere O, Thabut G, Krawice-Radanne I, Rizzo R, Dauriat G, Danel C, et al. Role of HLA-G as a Predictive Marker of Low Risk of Chronic Rejection in Lung Transplant Recipients: A Clinical Prospective Study. Am J Transplant (2015) 15:461-71. doi: 10.1111/ajt.12977

57. Ezeakile M, Portik-Dobos V, Wu J, Horuzsko DD, Kapoor R, Jagadeesan M, et al. HLA-G Dimers in the Prolongation of Kidney Allograft Survival. J Immunol Res (2014) 2014:153981. doi: 10.1155/2014/153981

58. Adamson MB, Di Giovanni B, Ribeiro R, Yu F, Lazarte J, Rao V, et al. HLA-G +3196 Polymorphism as a Risk Factor for Cell Mediated Rejection Following Heart Transplant. Hum Immunol (2020) 81:134-40. doi: 10.1016/ j.humimm.2020.01.002

59. von Websky MW, Kitamura K, Ludwig-Portugall I, Kurts C, von Laffert M, LeMaoult J, et al. Recombinant HLA-G as Tolerogenic Immunomodulant in Experimental Small Bowel Transplantation. PloS One (2016) 11:e158907. doi: 10.1371/journal.pone.0158907

60. Huang $\mathrm{H}, \mathrm{Lu}$ Y, Zhou T, Gu G, Xia Q. Innate Immune Cells in Immune Tolerance After Liver Transplantation. Front Immunol (2018) 9:2401. doi: 10.3389/fimmu.2018.02401

61. Yazdani S, Callemeyn J, Gazut S, Lerut E, de Loor H, Wevers M, et al. Natural Killer Cell Infiltration is Discriminative for Antibody-Mediated Rejection and Predicts Outcome After Kidney Transplantation. Kidney Int (2019) 95:18898. doi: 10.1016/j.kint.2018.08.027
62. Xu Z, Tsai HI, Xiao Y, Wu Y, Su D, Yang M, et al. Engineering Programmed Death Ligand-1/Cytotoxic T-Lymphocyte-Associated Antigen-4 Dual-Targeting Nanovesicles for Immunosuppressive Therapy in Transplantation. ACS Nano (2020) 14:7959-69. doi: 10.1021/acsnano.9b09065

63. Del BA, Zakaroff GA, Meyer N, Delas A, Faguer S, Kamar N, et al. Cytokine Storm Induced by a PD1 Inhibitor in a Renal Transplant Patient. Am J Transplant (2021) 21:2616-8. doi: 10.1111/ajt.16589

64. Nguyen LS, Ortuno S, Lebrun-Vignes B, Johnson DB, Moslehi JJ, Hertig A, et al. Transplant Rejections Associated With Immune Checkpoint Inhibitors: A Pharmacovigilance Study and Systematic Literature Review. Eur J Cancer (2021) 148:36-47. doi: 10.1016/j.ejca.2021.01.038

65. Porrett PM. Biologic Mechanisms and Clinical Consequences of Pregnancy Alloimmunization. Am J Transplant (2018) 18:1059-67. doi: 10.1111/ajt.14673

66. Cohen JB, Owei L, Sawinski DL, Porrett PM. Inferior Long-Term Allograft and Patient Outcomes Among Recipients of Offspring Living Donor Kidneys. Am J Transplant (2018) 18:1699-709. doi: 10.1111/ajt.14631

67. Bromberger B, Spragan D, Hashmi S, Morrison A, Thomasson A, Nazarian S, et al. Pregnancy-Induced Sensitization Promotes Sex Disparity in Living Donor Kidney Transplantation. J Am Soc Nephrol (2017) 28:3025-33. doi: 10.1681/ASN.2016101059

68. Redfield RR, Scalea JR, Zens TJ, Mandelbrot DA, Leverson G, Kaufman DB, et al. The Mode of Sensitization and its Influence on Allograft Outcomes in Highly Sensitized Kidney Transplant Recipients. Nephrol Dial Transplant (2016) 31:1746-53. doi: 10.1093/ndt/gfw099

69. Higgins R, Lowe D, Daga S, Hathaway M, Williams C, Lam FT, et al. Pregnancy-Induced HLA Antibodies Respond More Vigorously After Renal Transplantation Than Antibodies Induced by Prior Transplantation. Hum Immunol (2015) 76:546-52. doi: 10.1016/j.humimm.2015.06.013

70. Choi JY, Kwon OJ, Kang CM. The Effect of Donor-Recipient Relationship on Long-Term Outcomes of Living Related Donor Renal Transplantation. Transplant Proc (2012) 44:257-60. doi: 10.1016/j.transproceed.2011.11.017

71. Ghafari A. Offspring-to-Mother and Husband-to-Wife Renal Transplantation: A Single-Center Experience. Transplant Proc (2008) 40:140-2. doi: 10.1016/j.transproceed.2007.11.062

72. Vilches M, Nieto A. Analysis of Pregnancy-Induced Anti-HLA Antibodies Using Luminex Platform. Transplant Proc (2015) 47:2608-10. doi: 10.1016/ j.transproceed.2015.09.032

73. Resse M, Paolillo R, Pellegrino MB, Costa D, Fiorito C, Santangelo M, et al. Effect of Single Sensitization Event on Human Leukocyte Antigen Alloimmunization in Kidney Transplant Candidates: A Single-Center Experience. Exp Clin Transplant (2018) 16:44-9. doi: 10.6002/ect.2016.0292

74. van Buren MC, Schellekens A, Groenhof T, van Reekum F, van de Wetering J, Paauw ND, et al. Long-Term Graft Survival and Graft Function Following Pregnancy in Kidney Transplant Recipients: A Systematic Review and MetaAnalysis. Transplantation (2020) 104:1675-85. doi: 10.1097/TP.0000000000003026

75. Kelly WW, Ziogas IA, Izzy M, Pai AK, Hafberg ET, Matsuoka LK, et al. Liver Transplantation for Congenital Hepatic Fibrosis. Transpl Int (2021) 4:128192. doi: $10.1111 /$ tri.13884

76. Kramer A, Boenink R, Stel VS, Santiuste DPC, Tomovic F, Golan E, et al. The ERA-EDTA Registry Annual Report 2018: A Summary. Clin Kidney J (2021) 14:107-23. doi: 10.1093/ckj/sfaa271

77. Suarez-Pierre A, Lui C, Zhou X, Fraser CR, Ferrigno AS, Etchill E, et al. Conditional Survival in Heart Transplantation: An Organ Procurement and Transplantation Network Database Analysis. Ann Thorac Surg (2020) 110:1339-47. doi: 10.1016/j.athoracsur.2020.02.014

78. Sen A, Callisen H, Libricz S, Patel B. Complications of Solid Organ Transplantation: Cardiovascular, Neurologic, Renal, and Gastrointestinal. Crit Care Clin (2019) 35:169-86. doi: 10.1016/j.ccc.2018.08.011

79. Otsuka S, Melis N, Gaida MM, Dutta D, Weigert R, Ashwell JD. Calcineurin Inhibitors Suppress Acute Graft-vs-Host Disease Via NFAT-Independent Inhibition of T Cell Receptor Signaling. J Clin Invest (2021) 131:e147683. doi: 10.1172/JCI147683

80. Cheung CY, Tang S. An Update on Cancer After Kidney Transplantation. Nephrol Dial Transplant (2019) 34:914-20. doi: 10.1093/ndt/gfy262

81. Anastasilakis AD, Tsourdi E, Makras P, Polyzos SA, Meier C, McCloskey EV, et al. Bone Disease Following Solid Organ Transplantation: A Narrative Review and Recommendations for Management From The European Calcified Tissue Society. Bone (2019) 127:401-18. doi: 10.1016/j.bone.2019.07.006 
82. Kumar R, Ison MG. Opportunistic Infections in Transplant Patients. Infect Dis Clin North Am (2019) 33:1143-57. doi: 10.1016/j.idc.2019.05.008

83. Manzia TM, Angelico R, Gazia C, Lenci I, Milana M, Ademoyero OT, et al. De Novo Malignancies After Liver Transplantation: The Effect of Immunosuppression-Personal Data and Review of Literature. World J Gastroenterol (2019) 25:5356-75. doi: 10.3748/wjg.v25.i35.5356

84. Liao JB, Fisher CE, Madeleine MM. Gynecologic Cancers and Solid Organ Transplantation. Am J Transplant (2019) 19:1266-77. doi: 10.1111/ajt.15292

Conflict of Interest: The authors declare that the research was conducted in the absence of any commercial or financial relationships that could be construed as a potential conflict of interest.
Publisher's Note: All claims expressed in this article are solely those of the authors and do not necessarily represent those of their affiliated organizations, or those of the publisher, the editors and the reviewers. Any product that may be evaluated in this article, or claim that may be made by its manufacturer, is not guaranteed or endorsed by the publisher.

Copyright (๑) 2021 Sun, $W u, X u, X u e, L u$ and Ji. This is an open-access article distributed under the terms of the Creative Commons Attribution License (CC BY). The use, distribution or reproduction in other forums is permitted, provided the original author(s) and the copyright owner(s) are credited and that the original publication in this journal is cited, in accordance with accepted academic practice. No use, distribution or reproduction is permitted which does not comply with these terms. 